\title{
Is There Association between Risky Sexual Behaviors and Depression Symptoms among Youth? A Case of Jimma University Students, Ethiopia
}

\author{
Yonas Tesfaye $\mathbb{D}$, ${ }^{1}$ Alemayehu Negash, ${ }^{2}$ Tsegaye Tewelde Gebrehiwot $\mathbb{D},{ }^{3}$ \\ Worknesh Tessema, ${ }^{2}$ Susan Anand, ${ }^{1}$ Gutema Ahmed, ${ }^{1}$ and Daniel Alemu ${ }^{4}$ \\ ${ }^{1}$ School of Nursing and Midwifery, Jimma University, Jimma, 378, Ethiopia \\ ${ }^{2}$ Department of Psychiatry, Jimma University, Jimma, Ethiopia \\ ${ }^{3}$ Department of Epidemiology and Biostatistics, Jimma University, Jimma, Ethiopia \\ ${ }^{4}$ Department of Psychiatry, Haramaya University, Harar, Ethiopia \\ Correspondence should be addressed to Yonas Tesfaye; yonastesfaye71@yahoo.com
}

Received 11 March 2019; Accepted 23 May 2019; Published 1 July 2019

Academic Editor: Lenin Pavón

Copyright (C) 2019 Yonas Tesfaye et al. This is an open access article distributed under the Creative Commons Attribution License, which permits unrestricted use, distribution, and reproduction in any medium, provided the original work is properly cited.

\begin{abstract}
Background. Risky Sexual Behaviors (RSB) and Depression symptoms expose young people to various reproductive health problems including sexually transmitted infections and HIV/AIDS. To date the link between these two major public health problems lacks empirical evidence in the context of higher education institutions in Ethiopia. Objective. The aim of this study was to assess association between risky sexual behavior and depression symptoms among Jimma University main campus students, Jimma, Ethiopia, 2016. Methods. An institution based quantitative cross sectional study was conducted. A pre-tested questionnaire and modified Beck Depression Inventory II were administered to 700 students, selected by multi-stage stratified sampling, from the main campus of Jimma University. Descriptive statistics, simple and multiple logistic regression models were used to analyze possible confounders. Presence of crude association between the dependent and independent variables was detected by bivariate logistic regression analysis. Variables with $\mathrm{p}$ value $<0.25$ in bivariate analysis were analyzed by multivariable logistic regression to exclude the confounders. Adjusted odd ratios with $95 \% \mathrm{CI}$ were computed to examine depression symptoms and other independent variables as predictors of RSB. Results. RSB were reported by $30.2 \%$ students. Out of $222(33.6 \%)$ students with depression symptoms 105 (47.3\%) reported RSB. Students with moderate depression symptoms are nearly two times more likely to experience risky sexual behavior than students with no depression symptoms (AOR 1.9, 95\% CI: 1-3.1). Students with severe depression symptoms are nearly two and half times more likely to experience RSB than students with no depression symptoms counterparts (AOR 2.6, 95\%CI: 1.35.1). Conclusion. RSB were high among students with depression symptoms in the main campus of Jimma University. To help students overcome the challenges, recommendation was given for concerted action from the University, governmental and NGO, and the surrounding community to establish support services and various reproductive and mental health awareness programs within the campus.
\end{abstract}

\section{Introduction}

The transition from adolescence to adult hood is characterized by sharp boundaries. It is a challenging time with regard to psychosocial development $[1,2]$

Physiological changes during adolescence may explain young peoples' motivation to explore a range of different activities and experiment in high-risk behaviors such as substance abuse and risky sexual activity [3]. Young adulthood is a challenging time with regard to psychosocial development. The struggle to find and test one's own identity, to "fit in," and to build self-esteem often takes place through experimentation in different areas of behavior, including sexual relation $[4,5]$

Adolescents and young adults have increased interest in the opposite sex, highly concerned with physical and sexual attractiveness, and are frequently changing relationships. Besides, risk takers are more likely to make decisions about 
the future without adequately considering the consequences [6]. Young age is both a period of opportunity as well as a time of vulnerability- a time of experimentation with new ideas and options and marked with vulnerability to health risk and those related to unsafe reproductive health outcomes [7]

Young age is also a critical developmental period when many youth begin to define and clarify their sexual values and start to experiment with sexual behaviors. Most of these youth are students and they are also at a high risk for unsafe sexual behaviors and problems like HIV/AIDS or STI, unwanted pregnancy, abortion, poor school performance, high school dropout rate, psycho-social problems, conduct disorder, divorce, and economic problems $[8,9]$

Students of higher institutions are the backbone of social development, asset the society, and are change agents on which the future fates of any nation relay. It is also clear that this group is on the way of transforming to adulthood; filled with ambition; and building their future academic and social career. Neglecting their sexual and reproductive health can lead to high socio-economic consequences both immediately and in the years ahead $[10,11]$

Risky sexual behaviors are behaviors that include engaging in sexual activity from an early age, inconsistent use of condoms during sexual intercourse, unprotected sexual intercourse, having sex with commercial sex workers, and the tendency to have multiple sexual partners [3, 12-14].

Risky sexual behaviors expose young adults to sexually transmitted disease like Human Immunodeficiency Virus (HIV), to unconsented (forceful sex \{rape\}), unplanned pregnancy, and abortion which can lead to death and disability [15].

Young people of 10-24 years of age make up one-quarter of the world's population. Furthermore, according to the 2012global Acquired Immunodeficiency (AIDS) report, the same age group made up $42 \%$ of all new HIV infections in 2010. As to the setting, according to the 2012 United Nations Program on HIV and AIDS (UNAIDS) Global report, SubSaharan Africa remains the most severely affected, where nearly one in every 20 adults (4.9\%) are living with HIV, which accounts for $69 \%$ of the people living with HIV worldwide $[3,16]$.

The onset of mental health problems and risky sexual behavior both reach a peak in young adulthood [5]. Poor mental health has strong associations with other health concerns in this age group, substance abuse, and violence $[4,5]$.

Depression in young adults is a serious public health problem and the source of immense human suffering. It disrupts the person's life during a critical period for learning and social development. University students are often undergoing role transitions - such as moving away from the family home for the first time, residing with other students, and experiencing reduced adult supervision; these changes may increase the risk of depression $[17,18]$

One of the most common mental health problems faced by youths is depression, with estimates of lifetime prevalence over the course of adolescence ranging from $15 \%$ to $20 \%$. High rates of sub threshold depressive symptoms among youths have also been reported [19].

While sexual risk behaviors and STI are risk factors for depression, depression also may increase susceptibility to risk sexual behaviors and infection [20]. Depression may impair cognitive function, memory, decrease impulse control, contribute to psycho-social impairment including emotional reactivity in peer relationships, reduce motivation, and increase fatalism. These depression-related effects may inhibit clear perception of the consequences risk sexual behaviors and the ability to prevent risk behavior [21].

Research has found depressive symptomatology among youth to be associated with earlier sexual debut, higher numbers of lifetime sexual partners, concurrent, multiple and casual sexual partnerships, substance use at last sex, pregnancy, non-use of contraception, perceived barriers to condom use, and having more risky partners [22, 23].

It is reasonably possible to assume that university students are educated, inspirational, flourished with information, and able to practice upon the information they receive and as a result, they are among the low risk population. Nevertheless, practical observation showed that for many campus students the opposite appears to be the case $[24,25]$.

\section{Materials and Methods}

2.1. Study Area and Period. The study was conducted in the main campus of Jimma University, April 5 to 20, 2016. Main campus has currently four colleges with total of thirty departments: College of Health Science (medicine, pharmacy, medical Laboratory, anesthesia, dentistry, nursing, midwifery, health officer, and environmental health departments), College of Natural and Computational Science (mathematics, sport, chemistry, physics, biology, statistics and information science departments), College of Social Science and Humanities (geography, history, Amharic, English, Afan Oromo, sociology, music, Oromo folklore, social work, and psychology departments), and College of Law and Governance (Law and Governance departments). There were 6,155 regular undergraduate students enrolled during the academic year.

2.2. Study Design. Institution based quantitative cross-sectional study was conducted.

\subsection{Population}

2.3.1. Source of Population. All regular undergraduate Jimma University main campus students.

2.3.2. Study Population. Selected regular undergraduate main campus students who are enrolled from $1^{\text {st }}$ year to $5^{\text {th }}$ year in 2015/16 academic calendar.

\subsection{Eligibility Criteria}

2.4.1. Inclusion Criteria. All regular undergraduate Jimma University main campus students who are enrolled in 2015/ 2016 academic calendar. 
2.4.2. Exclusion Criteria. Students who had accidental illness during data collection period which make them incapable of participating in the study.

2.5. Sample Size Determination. The sample size was determined by single population proportion formula by assuming prevalence of risky sexual behavior rate of $31.4 \%$, according to the study done in Arbaminch university [14] with 5\% margin of error and 95\% confidence interval of certainty (alpha = $0.05)$.

The actual sample size for the study was computed using the following formula;

$$
\mathrm{n}=\frac{(\mathrm{z} \alpha / 2)^{2} \mathrm{P}(1-\mathrm{p})}{\mathrm{d}^{2}}
$$

where

$\mathrm{n}=$ Sample size

$\mathrm{z}=$ critical value 1.96

$\alpha / 2=$ confidence level

$\mathrm{P}=$ prevalence of risky sexual behavior at Arbaminch university students $=0.314$. [14]

$\mathrm{d}=$ margin of error $=0.05(5 \%)$

Therefore the value of $\mathrm{n}$ is calculated as follows:

$$
\begin{aligned}
\mathrm{n} & =\frac{(1.96) 2 \times 0.314(1-0.314)}{(0.05) 2} \\
& =330.99 \text { approximately } 331
\end{aligned}
$$

Since the total population is less than ten thousands correction formula was used to get the desired sample size

$$
\begin{aligned}
& \mathrm{nf}=\frac{\mathrm{n}}{(1+\mathrm{n} / \mathrm{N})} \\
& \mathrm{nf}=\frac{331}{(1+331 / 6155)}=314.1 \text { approximately } 315
\end{aligned}
$$

Since the sampling is multistage, design effects of 2 were taken, $315 \times 2$, then it becomes 630 .

Finally with addition of $10 \%$ non-response rate the required sample size becomes 700 .

2.6. Sampling Technique and Procedures. Multistage stratified sampling technique was used to select the study participants. All four colleges were included. Stratification has been done on department and year of study level. From the thirty departments in the four colleges, eleven departments were selected by simple random sampling lottery method. From these departments, after proportionate allocation of the students for each year of study (first year to fifth year), simple random sampling technique was used to select 700 students, using the enrollment register as a frame.

\subsection{Variables}

\section{Dependent Variables}

(i) Risky sexual behavior (presence or absence)
Independent Variable

Socio Demographic Economic Variables

(i) Age

(ii) Sex

(iii) Religion

(iv) Ethnicity

(v) Marital status

(vi) Pocket money

(vii) Place of Growing

(viii) Participation in Religious Education

\section{Educational Related Factors}

(i) Department/ field of study

(ii) Year of study

\section{Mental Health Factor}

(i) Depression

\section{Substance Related Factors}

(i) Khat use

(ii) Alcohol Consumption

Family Related Factors

(i) Living Arrangements

(ii) Educational level of parents

(iii) Discussion with parents on sexual matters

Factors Influencing for Acquirement of Risky Sexual Behavior

(i) Watch pornographic movie

(ii) Attending night clubs

(iii) Peer pressure to engage into risky sexual behaviors

2.8. Data Collection Instruments and Procedures. A structured, self-administered questionnaire consisting of five different sub-sections was used. The questionnaire has sociodemographic, depression symptoms, Khat chewing/use, Alcohol consumption, and Risky sexual behaviors sections. The research tool was developed after extensive literature search. For risky sexual behavior assessment tool, face validity test by three independent experts on the field was performed and reliability test was done with Cronbach alpha result of 0.78. Beck Depression Inventory- II (BDI-II) was used to evaluate severity of depression symptoms with good psychometric property.

The questionnaire was prepared in English, then translated into the local languages, Amharic and Afan Oromo and back translated to English by language experts, so as to 
ensure its consistency. Finally, the Amharic and Afan Oromo versions of the questionnaires were used to collect data based on the respondent's language preference.

The data collectors were five BSc psychiatry nurses. Data collectors and supervisors were trained for two days by the principal investigator on the objective, purpose of the study, and data collection procedure.

2.9. Data Quality Management. Regular supervision was made by the supervisor and the principal investigator to ensure that all necessary data are properly collected. Each day of data collection, the filled questioners were cheeked manually first for completeness and consistency then the collected data were processed timely and entered from a paper onto computer twice. Pre-test was conducted before the main study on 35 students (5\% of the sample size) at Jimma University college of Agriculture and Veterinary Medicine to identify impending problems on data collection tools. Data collected in the pre-test were not included in the analysis as part of the main study.

2.10. Data Processing, Analysis and Interpretation. The collected data were checked manually for completeness and consistency, cleaned, coded and entered, into Epi-data version 3.1, and exported to SPSS version 20 statistical software for analysis. Descriptive statistics were done to summarize the dependent and independent variables. Logistic regression model was used to analyze the predictors of risky sexual behavior. Bivariate logistic regression was done and variables with p-value less than or equal to 0.25 were entered into multivariate logistic regression, then variables with $\mathrm{p}$ value $<0.05$ at $95 \%$ confidence interval were considered as statistically significant association with the outcome variable.

\subsection{Operational and Term Definitions}

Sex Contact. Voluntary or involuntary sexual intercourse.

Sexual Experience. The experience of having sexual intercourse.

Risky Sexual Behavior (RSB). Not using condom or inconsistent use of condoms, or having multiple sexual partner or early initiation of sex or sex with commercial sex workers. Participants who are engaged into at least one of the above behaviors were considered as having risky sexual behavior and those who were not engaged into non-of the above behaviors were considered as not having risky sexual behavior[3, 25].

Not Using Condom. Never used condom on sexual intercourse until the survey.

Inconsistent Use of Condom. Fail to use condom at least ones during sexual intercourse until the survey.

Having Multiple Sexual Partners. Participants who had two or more sexual partners until the survey.
Early Initiation of Sex. Participants who start sex before age 18 years.

Sex with Commercial Sex Workers. Sexual act with those who do sex for exchange of money until the survey.

Depression Symptoms. Measured by Beck Depression Inventory- II (BDI-II). The scores are interpreted as 0 to 13 indicating no or minimal, 14 to 19 mild, 20 to 28 Moderate, and 29 to 63 severe depression symptoms [26].

Substance- in this study includes Khat and Alcohol.

Alcohol Consumption. It was measured by AUDIT. AUDIT score of 1-7 indicates social drinking, Score of 8-15 "hazardous drinking", Score of 16-19 "harmful drinking" Score of 20 or above probable alcohol dependence. Participants with AUDIT score of eight or more will be used to define probable 'alcohol use disorder [27].

Khat Use. Measured by- Life time Prevalence of Khat use is the proportion of student who had ever used or chewed Khat and Current Prevalence of Khat use is the proportion of students who use or chew currently and have chewed within month of data collection.

2.12. Ethics and Consent. The proposal of this study was reviewed and approved by Institutional Review Board (IRB) of Jimma University. Written consent was obtained from participants after explaining the purpose of the study. Participants were assured that their names will not be stated; data were kept confidential \& anonymous and used only for research purpose. Study participant with problem related to Alcohol consumption, depression symptoms, and having suicidal thought are linked to nearby mental health service providing facility.

\section{Results}

The questionnaires were completed by 660 students.

3.1. Socio Demographic Characteristics of Participants. Majority of the respondents were males $(n=422,63.9 \%)$, unmarried $(\mathrm{n}=568,86.1 \%)$ with mean age of $21.29(\mathrm{SD}+1.92)$ years. They were predominantly Orthodox Christians $(n=269,40.8 \%)$ and Muslims ( $n=201,30.5 \%)$. Maximum representation was by Oromo and Amhara ethnic tribes $(n=352,53.3 \%$; $n=155$, $23.5 \%)$. Most of them were from the College of Health Science $(n=273,41.4 \%)$, pursuing first year of study $(n=208,31.5 \%)$. See Table 1.

3.2. Prevalence of Risky Sexual Behavior. The prevalence of RSB among Jimma University main campus regular undergraduate students was $30.2 \%(n=199)$.

3.3. Factors Influencing the Acquirement of Risky Sexual Behavior. Majority of the respondents did not watch porn movies ( $\mathrm{n}=386,58.5 \%)$ nor attend night clubs ( $\mathrm{n}=517,78.3 \%)$. There was no peer pressure to engage in risky sexual behaviors $(\mathrm{n}=492,74.5 \%)$, and $80.8 \%(\mathrm{n}=533)$; students reported it 
TABle 1: Socio demographic, economic, and academic and parent's characteristics of Jimma University students, April, 2016.

\begin{tabular}{|c|c|c|c|}
\hline & Characteristics & Frequency $(\mathrm{n}=660)$ & Percentage \\
\hline \multirow{2}{*}{ Sex } & Male & 422 & 63.9 \\
\hline & Female & 238 & 36.1 \\
\hline \multirow{3}{*}{ Age } & $18-20$ & 273 & 41.4 \\
\hline & $21-23$ & 305 & 46.2 \\
\hline & $>=24$ & 82 & 12.4 \\
\hline \multirow{2}{*}{ Marital status } & Married & 73 & 11.1 \\
\hline & Unmarried & 587 & 88.9 \\
\hline \multirow{6}{*}{ Ethnicity } & Oromo & 352 & 53.3 \\
\hline & Amhara & 235 & 23.5 \\
\hline & Gurage & 52 & 7.9 \\
\hline & Tigre & 39 & 5.9 \\
\hline & Yem & 28 & 4.2 \\
\hline & Others & 34 & 5.2 \\
\hline \multirow{6}{*}{ Religion } & Orthodox & 269 & 40.8 \\
\hline & Islam & 202 & 30.5 \\
\hline & Protestant & 156 & 23.6 \\
\hline & wakefeta & 21 & 3.2 \\
\hline & Catholic & 8 & 1.2 \\
\hline & Others & 5 & 0.8 \\
\hline \multirow{2}{*}{ Living Residence before joining university } & Rural & 270 & 40.9 \\
\hline & Urban & 390 & 59.1 \\
\hline \multirow{2}{*}{ Living arrangement } & Living with parent & 107 & 16.2 \\
\hline & Living away from parent & 553 & 83.8 \\
\hline \multirow{2}{*}{ Current living residence } & In dormitory & 494 & 89.3 \\
\hline & Outside dormitory in rented house & 59 & 10.7 \\
\hline \multirow{2}{*}{ Participation in religious education } & Yes & 539 & 81.7 \\
\hline & No & 121 & 18.3 \\
\hline \multirow{5}{*}{ Average Monthly pocket money(birr) } & None & 46 & 7.0 \\
\hline & $<100$ & 85 & 12.8 \\
\hline & $100-299$ & 153 & 23.2 \\
\hline & $300-499$ & 241 & 36.5 \\
\hline & $\geq 500$ & 135 & 20.5 \\
\hline \multirow{4}{*}{ College } & Health science & 273 & 41.4 \\
\hline & Law and governance & 155 & 23.5 \\
\hline & Social science and humanities & 150 & 22.7 \\
\hline & Natural and computational science & 82 & 12.4 \\
\hline \multirow{5}{*}{ Year of study } & Year I & 208 & 31.5 \\
\hline & Year II & 170 & 25.8 \\
\hline & Year III & 128 & 20.9 \\
\hline & Year IV & 90 & 13.6 \\
\hline & Year V & 54 & 8.2 \\
\hline \multirow{4}{*}{ Mother's educational status } & Illiterate & 165 & 25.0 \\
\hline & Primary school & 281 & 42.6 \\
\hline & Secondary school & 129 & 19.5 \\
\hline & University/ collage & 85 & 12.9 \\
\hline \multirow{4}{*}{ Father's educational status } & Illiterate & 108 & 16.4 \\
\hline & Primary school & 231 & 35.0 \\
\hline & Secondary school & 202 & 30.6 \\
\hline & University/ collage & 119 & 18.0 \\
\hline
\end{tabular}

Other ethnicity= Wolayta, Sidama, Kafa, Hadiya, and Silte.

Other religion = Giova witness, Adventist, atheist. 
TABLE 2: Factors influencing acquirement of risky sexual behavior among Jimma University students, April, 2016.

\begin{tabular}{lcc}
\hline Characteristics & Frequency $(\mathrm{n}=660)$ & Percentage \\
\hline Watching pornographic movie & 274 & 41.5 \\
Yes & 386 & 58.5 \\
No & & \\
\hline Attending night clubs & 143 & 21.7 \\
Yes & 517 & 78.3 \\
No & & \\
\hline Peer pressure to engage in risky sexual behaviors & 168 & 25.5 \\
Yes & 492 & 74.5 \\
No & & 127 \\
\hline Discussion with parents on sexual matters & 533 \\
Yes & & 80.8 \\
No &
\end{tabular}

was taboo to openly discuss sexual issues with parents. See Table 2.

3.4. Depression Symptoms. The BDI-II, which was used to identify depressive symptoms and its severity, found $29.1 \%$ $(\mathrm{n}=192)$ respondents had depression symptoms, among them $88(\mathrm{n}=13.3 \%)$ had mild depression symptoms, $81(\mathrm{n}=12.3 \%)$ had moderate depression symptoms, and $23(n=3.5 \%)$ had severe depression symptoms.

3.5. Sexual Practice and Risky Sexual Behavior. Out of 660 students participating in the study, 35.5\% $(n=234)$ participants reported sexual intercourse, $61.1 \%(n=143)$ of them had multiple sexual partners, and 59.8\% $(n=140)$ had sexual relation within last 1 year. Majority of these sexually active participants between 14-25 years had early sexual initiation $44.9 \%(n=105)$. Although majority of them reported use of condom $(n=164,70.1 \%), 29.9 \%(n=70)$ had not used condoms. Among the condom users, majority $59.8 \%(n=98)$ always used condom during coitus, whereas $24.4 \%(n=40)$ reported occasional use. Sex with commercial sex workers was reported by $5.5 \%(n=36)$, among them all are those who had reported sexual experience. See Table 3.

3.6. Factors Associated with Risky Sexual Behavior. Age, sex, marital status, current living condition, attending religious education, mother education attending night clubs, watching pornographic movies, peer pressure to engage in risky sexual behaviors, having depression symptoms, having alcohol use disorder showed highly significant association with risky sexual behavior $(\mathrm{P} \leq 0.25)$ and were further analyzed by multivariate logistic regression to control the confounders.

Depression symptoms, probable alcohol use disorder, watching pornographic movie, not participating in religious education, and having peer pressure to engage in risky sexual behaviors were independent predictors of risky sexual behavior.

Students with moderate depression symptoms are nearly two times more likely to indulge in risky sexual behavior than students with no depression symptoms (AOR 1.9, 95\%CI: 1.1-3.1). Also students with severe depression symptoms are nearly two and half times more likely to experience risky sexual behavior than students with no depression symptoms (AOR 2.6, 95\%CI: 1.3- 5.1). Having alcohol use disorder students are nearly three times more likely to experience risky sexual behavior than the non-drinker counterparts (AOR 2.9, 95\%CI: 1.4-6.1). Students who chewed Khat 2-4 times a month are approximately three times more likely to experience risky sexual behavior than the non-chewer counterparts (AOR:2.8, 95\%CI: 1.1-7.7). Students who chewed Khat 2-3 times a week are approximately four and half times more likely to experience risky sexual behavior than the nonchewer counterparts (AOR 4.3,95\% CI: 1.1-17.6). Students who didn't participate in religious education are nearly two times more likely to experience risky sexual behavior than their counterpart (AOR 1.9, 95\%CI: 1.1-3.2). Students who watched pornographic movies are approximately four times more likely to experience risky sexual behaviors (AOR 4.1, 95\%CI: 2.6-6.5). Students who had peer pressure to engage in risky sexual behaviors are approximately one and half times more likely to experience risky sexual behaviors (AOR 1.6, 95\%CI: 1.1-2.7). See Table 4.

The level of depression symptoms in students, among other factors, was found to be significantly associated with involvement in risky sexual behaviors. Thus, students with moderate depression symptoms (AOR 1.9, 95\%CI: 1.1-3.1), severe depression symptoms (AOR 2.6, 95\%CI: 1.3- 5.1), alcohol use disorder (AOR 2.9, 95\%CI: 1.4-6.1), chewing Khat (AOR 2.8, 95\%CI: 1.1-7.7), avoiding religious education (AOR 1.9, 95\%CI: 1.1-3.2), watching pornographic movies (AOR 4.1, 95\%CI: 2.6-6.5), and peer pressure for risky sexual practices (AOR 1.6, 95\%CI: 1.1-2.7) were more likely to indulge in risky sexual behaviors. See Table 5.

\section{Discussion}

This study was planned to assess the association of risky sexual behavior with depression symptoms among Jimma University main campus students, Ethiopia. 
TABle 3: Participant's sexual practices and risky sexual behavior of Jimma University students, April, 2016.

\begin{tabular}{|c|c|c|c|}
\hline Variables & Characteristics & Frequency & Percentage $(100 \%)$ \\
\hline \multirow{2}{*}{ Sexual experience } & No & 426 & 64.5 \\
\hline & Yes & 234 & 35.5 \\
\hline \multirow{3}{*}{ Sex in the last 12 months (sexually active) } & Yes & 140 & 59.8 \\
\hline & No & 94 & 40.2 \\
\hline & Total & 234 & 100 \\
\hline \multirow{4}{*}{ Number of sexual partners } & No & 426 & 64.5 \\
\hline & 1 & 91 & 38.9 \\
\hline & $>1$ & 143 & 61.1 \\
\hline & Total & 234 & 100 \\
\hline \multirow{3}{*}{ Age at first sexual intercourse } & $>=18$ & 129 & 55.1 \\
\hline & $<18$ & 105 & 44.9 \\
\hline & total & 234 & 100 \\
\hline \multirow{3}{*}{ Condom use } & Yes & 164 & 70.1 \\
\hline & No & 70 & 29.9 \\
\hline & Total & 234 & 100 \\
\hline \multirow{4}{*}{ Frequency of condom use } & Always & 98 & 59.8 \\
\hline & Occasionally & 40 & 24.4 \\
\hline & rarely & 26 & 15.8 \\
\hline & total & 164 & 100 \\
\hline \multirow{3}{*}{ Sex with commercial sex workers } & yes & 36 & 5.5 \\
\hline & No & 624 & 94.5 \\
\hline & total & 660 & 100 \\
\hline
\end{tabular}

The prevalence of risky sexual behaviors was $30.2 \%$; similar findings were reported from Arbaminch University $31.4 \%$ [14], but much lower compared to Haramaya University students, where $65.8 \%$ of the participants had practiced at least one of the risky sexual behaviors. In the study done at Haramaya University, the prevalence of risky sexual behavior was calculated from only those students who were sexually active, unlike the case in this study where the prevalence was calculated from all the study participants [25] but much higher than Humera secondary school which was 13.7\% [13]. College life gives students sense autonomy. Being away from parental constraints and influenced by friends, students could go in pursuit of forbidden pleasures such as substance use and seek sexual gratification from commercial sex workers.

The study revealed $44.9 \%$ students had early sexual debut (<18years); similar findings were reported in Haramaya University $43.5 \%$ [25] but higher than the findings from Bahir Dar University $24.3 \%$ [15]. The findings are comparatively lower than those of the report from Cameroon University $55 \%$ [28]. This is another nation, culturally different. Lower findings in studies done six years ago at Jimma University and Bahir Dar University $75.6 \%$ and $72.8 \%$ respectively are explained by the obvious time gap and the media interventions on sexual health $[10,15]$.

There was an increase in students having multiple sexual partners in the current study $(61.1 \%)$, overtaking the results reported six years ago in the same University $28.3 \%$ [10]. and other research findings from Bahir Dar University 42.7\%, Jigjiga university 30.1\%, Mekelle University $47.4 \%$, and tertiary institution in Nigeria $48.2 \%$ [15, 17, 29, 30]. The growing influence of social media and covert peer pressure in the campus may be promoting sexual promiscuity.

A little more than one-fourth of the students (29.9\%) had never used condom and the rest (70.1\%) used condoms during casual sex. But only a little more than half of them (59.8\%) always used condom whereas $24.4 \%$ used occasionally and the remaining $15.8 \%$ rarely used. The study done in Bahir Dar university reported similar findings for inconsistent condom use and never use of condom 36\% and $25 \%$ respectively [15]. Our findings are comparable to the study conducted in Mekelle University in which among those who used condom $50.5 \%$ were inconsistent condom users [30]. In Madagascar University 57.6\% of the respondents used condom inconsistently [31]. But our finding was higher than that of the study done in Kenya, Nairobi University students and Colombia with inconsistent condom use by $27.4 \%, 33.7 \%$ respondents respectively $[23,32]$. This disparity may be explained by the difference in culture of using condom between the two countries.

Sex with commercial sex workers was reported by $5.5 \%$ students compared to 8.8\% from Arbaminch University, 7.4\% Bahir Dar University, 31.9\% Haramaya University, $16.3 \%$ Jigjiga University, and $8.8 \%$ Gondar University respectively $[14,15,25,29,33]$. 
TABLE 4: Bivariate analysis of factors associated with risky sexual behavior among Jimma university students, April 2016.

\begin{tabular}{|c|c|c|c|c|c|}
\hline & \multirow{2}{*}{ Characteristics } & \multicolumn{2}{|c|}{ Risky sexual behavior } & \multirow[t]{2}{*}{ COR (CI-95\%) } & \multirow[t]{2}{*}{ P value } \\
\hline & & Yes & No & & \\
\hline \multirow{2}{*}{ Sex } & Male & $149(74.9 \%)$ & $273(59.2 \%)$ & $2.0(1.4-2.9)$ & $<0.001 *$ \\
\hline & Female & $50(5.1 \%)$ & $188(40.8 \%)$ & 1 & \\
\hline \multirow{3}{*}{ Age } & $18-20$ & $71(26.0 \%)$ & $202(74.0 \%)$ & 1 & \\
\hline & $21-23$ & $92(30.2 \%)$ & $213(69.8 \%)$ & $1.2(0.8-1.7)$ & 0.268 \\
\hline & $>=24$ & $36(43.9 \%)$ & $46(56.1 \%)$ & $2.2(1.3-3.7)$ & $0.002 *$ \\
\hline \multirow{2}{*}{ Marital status } & Married & $46(63.0 \%)$ & $27(37.0 \%)$ & $1.4(0.8-2.3)$ & $0.179 *$ \\
\hline & Unmarried & $415(70.7 \%)$ & $199(29.3 \%)$ & 1 & \\
\hline \multirow{2}{*}{ Living residence before joining university } & Rural & $88(32.6 \%)$ & $182(67.4 \%)$ & $1.2(0.8-1.7)$ & 0.256 \\
\hline & Urban & $111(28.5 \%)$ & $279(71.5 \%)$ & 1 & \\
\hline \multirow{2}{*}{ Living arrangement } & Living with parent & $37(34.6 \%)$ & $70(65.4 \%)$ & $1.2(0.8-1.9)$ & 0.276 \\
\hline & Living away from parent & $162(29.3)$ & $391(70.7 \%)$ & 1 & \\
\hline \multirow{2}{*}{ Current living condition } & In dormitory & $22(37.3 \%)$ & $37(62.7 \%)$ & $1.5(0.8-2.6)$ & $0.156 *$ \\
\hline & Outside dormitory in rented house & $140(28.3 \%)$ & $354(71.7 \%)$ & 1 & \\
\hline \multirow{2}{*}{ Participation in religious education } & Yes & $137(25.4 \%)$ & $402(74.6 \%)$ & 1 & \\
\hline & No & $62(51.2 \%)$ & $59(4.8 \%)$ & $3.0(2.0-4.6)$ & $<0.001 *$ \\
\hline \multirow{5}{*}{ Monthly Pocket money(birr) } & None & $14(30.4 \%)$ & $32(69.6 \%)$ & $0.8(0.4-1.7)$ & 0.651 \\
\hline & $<100$ & $29(34.1 \%)$ & $56(65.9 \%)$ & $1(0.5-1.7)$ & 0.995 \\
\hline & $100-299$ & $52(34.0 \%)$ & $101(66.0 \%)$ & $1(0.6-1.6)$ & 0.987 \\
\hline & $300-499$ & $58(24.1 \%)$ & $183(75.9 \%)$ & $0.6(0.3-1.1)$ & 0.388 \\
\hline & $\geq 500$ & $46(34.1 \%)$ & $89(65.9 \%)$ & 1 & \\
\hline \multirow{4}{*}{ Collage } & Health science & $78(28.6 \%)$ & $195(41.4 \%)$ & 1 & \\
\hline & Law and governance & $46(30.7 \%)$ & $104(69.3 \%)$ & $1.2(0.8-1.9)$ & 0.282 \\
\hline & Social science and humanities & $23(28.0 \%)$ & $59(72.0 \%)$ & $1.1(0.7-1.7)$ & 0.651 \\
\hline & Natural and computational science & $52(33.5 \%)$ & $103(66.5 \%)$ & $0.9(0.5-1.6)$ & 0.927 \\
\hline \multirow{5}{*}{ Year of study } & Year I & $54(26.0 \%)$ & $154(74.0 \%)$ & 1 & \\
\hline & Year II & $48(28.3 \%)$ & $122(71.8 \%)$ & $1.1(0.7-1.7)$ & 0.620 \\
\hline & Year III & $46(33.3 \%)$ & $92(66.7 \%)$ & $1.4(0.8-2.2)$ & 0.139 \\
\hline & Year IV & $27(30.0 \%)$ & $63(70.0 \%)$ & $1.2(0.7-2.1)$ & 0.472 \\
\hline & Year VI & $24(44.4 \%)$ & $30(55.6 \%)$ & $2.2(1.2-4.2)$ & $0.009 *$ \\
\hline \multirow{4}{*}{ Mother education level } & Illiterate & $56(33.9 \%)$ & $109(66.1 \%)$ & 1 & \\
\hline & Primary school & $85(30.2 \%)$ & $196(69.8 \%)$ & $0.8(0.5-1.2)$ & 0.419 \\
\hline & Secondary school & $34(26.4 \%)$ & $95(73.6 \%)$ & $0.6(0.4-1.1)$ & $0.162 *$ \\
\hline & University/ collage & $24(28.2 \%)$ & $61(71.8 \%)$ & $0.7(0.4-0.3)$ & 0.360 \\
\hline \multirow{4}{*}{ Father education level } & Illiterate & $34(31.5 \%)$ & $74(68.5 \%)$ & $1.1(0.6-2.1)$ & 0.536 \\
\hline & Primary school & $68(29.4 \%)$ & $163(70.6 \%)$ & $1.0(0.6-1.7)$ & 0.739 \\
\hline & Secondary school & $64(31.7 \%)$ & $138(68.3 \%)$ & $1.2(0.7-1.9)$ & 0.457 \\
\hline & University/ collage & $33(27.7 \%)$ & $86(72.3 \%)$ & 1 & \\
\hline \multirow{2}{*}{ Watch pornographic movie } & Yes & $135(49.3 \%)$ & $139(50.7 \%)$ & $4.8(3.4-6.9)$ & $<0.001 *$ \\
\hline & No & $64(16.6 \%)$ & $322(83.4 \%)$ & 1 & \\
\hline \multirow{2}{*}{ Attending night clubs } & Yes & $82(57.3 \%)$ & $61(42.7 \%)$ & & \\
\hline & No & $117(22.6 \%)$ & $400(77.4 \%)$ & $4.5(3.1-6.7)$ & $<0.001 *$ \\
\hline \multirow{2}{*}{ Peer pressure to engage into risky sexual behavior } & Yes & $80(47.6 \%)$ & $88(52.4 \%)$ & $2.8(1.9-4.1)$ & $<0.001 *$ \\
\hline & No & $119(24.2 \%)$ & $373(75.8)$ & 1 & \\
\hline \multirow{2}{*}{ Discussion with parents on sexual matters } & Yes & $40(31.5 \%)$ & $87(68.5 \%)$ & $1.0(0.7-1.6)$ & 0.713 \\
\hline & No & $159(29.8 \%)$ & $374(70.2 \%)$ & 1 & \\
\hline & $\mathrm{No} / \mathrm{minimal}(0-13)$ & $108(23.1 \%)$ & $360(76.9 \%)$ & 1 & \\
\hline Ievel of denrecsion cumntoms (BDI ccore) & Mild (14-18) & $43(48.9 \%)$ & $45(51.1 \%)$ & $1.3(0.8-2.1)$ & $0.158 *$ \\
\hline Level or depression symptoms (BDI score) & Moderate (19-28) & $35(43.2 \%)$ & $46(56.8 \%)$ & $3.4(2.1-5.6)$ & $<0.001 *$ \\
\hline & Severe (29-63) & $13(56,5 \%)$ & $10(43.5 \%)$ & $3.4(2.0-5.7)$ & $<0.001 *$ \\
\hline Alcohol & Had probable alcohol use disorder & $44(73.3 \%)$ & $16(26.7 \%)$ & $7.8(4.3-14.3)$ & $<0.001 *$ \\
\hline & Had no alcohol use disorder & $155(25.8 \%)$ & $445(74.2 \%)$ & 1 & \\
\hline
\end{tabular}


TABLE 4: Continued.

\begin{tabular}{lccccc}
\hline \multirow{2}{*}{ Characteristics } & \multicolumn{2}{c}{ Risky sexual behavior } & \multicolumn{2}{c}{ COR (CI-95\%) } & P value \\
& & Yes & No & & \\
\hline & Never chewed & $119(24.7 \%)$ & $362(75.3 \%)$ & 1 & \\
Frequency of Khat use & Monthly or less & $45(36.3 \%)$ & $79(63.7 \%)$ & $1.7(1.1-2.6)$ & 0.100 \\
& $2-4$ times a month & $19(61.3 \%)$ & $12(38.7 \%)$ & $4.8(2.2-10.2)$ & $<0.001 *$ \\
& $2-3$ times a week & $13(68.4 \%)$ & $6(31.6 \%)$ & $6.5(2.4-17.7)$ & $<0.001 *$ \\
& 4 or more times a week & $3(60.0 \%)$ & $2(40.0 \%)$ & $4.5(0.7-27.6)$ & 0.999 \\
\hline
\end{tabular}

* Variables which were associated with risky sexual behavior in the bivariate analysis BDI- Beck Depression Inventory

AUDIT- Alcohol Use Disorder Identification Test

1-Reference.

The risk of engaging in risky sexual behaviors was four times higher among those who watched pornographic movies than their counterparts, consistent with studies from MizanTepi University indicating three times increased risk for risky sexual behaviors [34]. This is also supported by study done in Bahir Dar University and Jimma University which found the risk was two times higher than those who were not exposed to porn movies respectively $[10,15]$. Pornographic movies can excite the students and put people at risk for unsafe sexual activities.

Peer pressure in the campus was another risk factor which exposed the students for risky sexual behaviors two times more than those who did not experience peer interference; a similar finding was revealed in a previous study in the same University [10]. At Humera secondary school, peer pressure increased the risk by three times [13]. Peers can be a negative influence on students with low self-esteem. The desire to be in the 'in -group' and being away from parental control are other reasons for many students to try out risky behaviors, often overlooking the painful consequences.

Students who participated in religious education were two times less likely to involve in risky sexual behaviors; the study among students of Humera secondary school also found religious education being a protective factor against exposure to risky sex. [13]

Risky sexual behaviors were reported by $30.2 \%$ students. Out of 222 (33.6\%) students with depression symptoms 105 (47.3\%) reported risky sexual behaviors. Moreover students with severe depression symptoms were two and half times more likely to engage in risky sexual behaviors than students with no depression symptoms ( $\mathrm{P}$ value of 0.003 ); this finding is in line with the study done among Nairobi University students, Kenya [23] and US middle and high school Students [35]. The possible explanations can come from Beck's cognitive theory of depression, which describes that negative feelings and thoughts play a central role in how people feel about themselves, which ultimately influences the behavior in which they engage. Such negative thoughts and cognitive distortions can deter rational decision-making and allow emotions to influence behavior. Thus, depressive symptoms may not support healthy decision making and subsequent healthy behavior, including safe sexual decision making and safe sex behavior [36]. Another explanation can be individuals with depressive symptoms may also use sexual risk behaviors as part of a coping response to their depressive symptoms and depression can unearth unbearable feelings that many people try to escape and patients attempt to seek relief from emotional pain which exposes them to selfdestructive behaviors such as substance use and indiscriminate sex. [37].

Another valid finding in this study, which has been supported by other literature from Uganda, Ireland and USA, was the higher risk for risky sexual behaviors among students with probable alcohol use disorders [38-40] Dependence on mind altering substances including alcohol, alters sound thinking and social judgment and therefore less likely to enact protective behaviors. Moreover the link between alcohol disorder and depression symptoms among these students may exist. The possible reason alcohol use increases risk of practicing risky sexual behavior in all studies may be due to the fact that alcohol interferes with judgment and decision making capacity which led the user to be involve in various risky sexual behaviors.

The use of Khat was another risk factor in this study which exposed students to risky sexual behaviors. In this study students who chewed Khat 2-4 times a month and 2-3 times a week were at higher risk to engage in to risky sexual behavior than those who never chewed, which has been confirmed by studies at Universities in Arbaminch, Bahir Dar and Haramaya [14, 15, 25]. Khat interferes with cognitive capacity and interferes with judgment and in some cases also increases sexual desire.

\section{Conclusion}

The prevalence of risky sexual behavior and depression symptoms among Jimma university main campus students was high and positively associated. Moreover, substance use, watching pornographic movie, having peer pressure to engage in risky sexual behaviors, and not participating in religious educations have found to increase the risk of experiencing risky sexual behavior.

\section{Data Availability}

The data used to support the findings of this study are available from the corresponding author upon request. Data underlying the findings of this paper will be publicly available. 


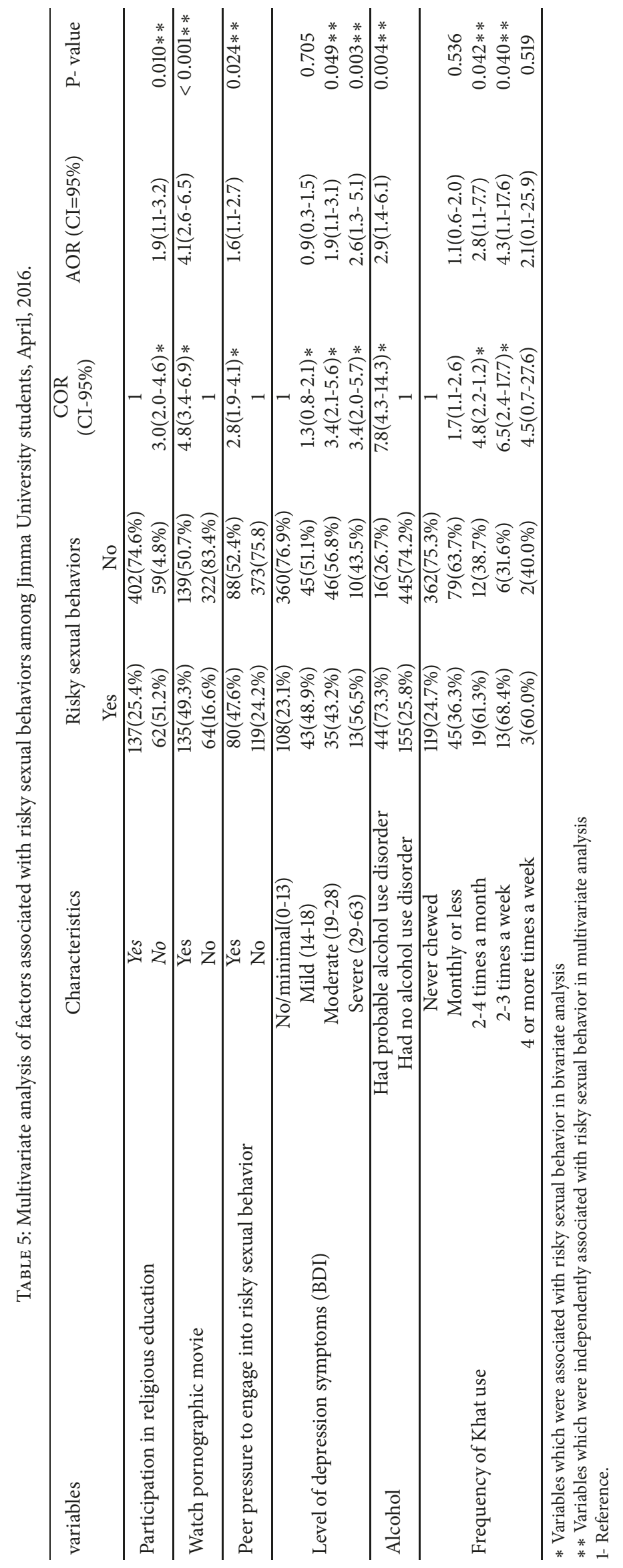




\section{Conflicts of Interest}

The authors declare that they have no competing interest.

\section{Acknowledgments}

We would like to thank Jimma University for funding this study. Our heartfelt appreciation extends to our study participants, data collection supervisors, academic and administrative staff of sampled departments for their time and hospitality. Finally yet importantly, we would like to thank all unnamed individuals for their support, advice, and help they offered us to finish the study.

\section{Supplementary Materials}

The supplementary material is a data set. All the research article result is generated from that data set. The data set includes all the variables with corresponding respondents response. The analysis results were also generated from that data set. Some variables are coded in different variables for description purpose. (Supplementary Materials)

\section{References}

[1] A. Martel and D. C. Fuchs, "Transitional age youth and mental illness - influences on young adult outcomes," Child and Adolescent Psychiatric Clinics of North America, vol. 26, no. 2, pp. xiii-xvii, 2017.

[2] D. R. Morgan, M. Robinson-Graves, and J. H. Gooding, "The Provider Toolkit for Emerging Adults with Serious Mental Health Conditions," 015, https://dbhdd.georgia.gov/sites/dbhdd .georgia.gov/files/related_files/site_page/HTIToolkit9.10.15.pdf.

[3] A. T. Gebremedhin, H. A. Gesesew, T. D. Demissie, M. W. Kerie, and M. Sudhakar, "Khat chewing and risky sexual behavior in Sub-Saharan Africa: a systematic review protocol," JBI Database of Systematic Reviews and Implementation Reports, vol. 11, no. 12, pp. 59-67, 2013.

[4] V. Patel, "Mental health in low- and middle-income countries," British Medical Bulletin, vol. 81-82, no. 1, pp. 81-96, 2007.

[5] A. Agardh, E. Cantor-Graae, and P. Östergren, "Youth, sexual risk-taking behavior, and mental health: a study of university students in Uganda," International Journal of Behavioral Medicine, vol. 19, no. 2, pp. 208-216, 2012.

[6] M. Kassa, E. Tesfaye, and Z. Alamrew, "Risky sexual behaviour among big construction enterprise workers; Bahir Dar City, Amhara Regional State, Northwest Ethiopia," International Journal of Clinical Medicine, vol. 04, no. 06, pp. 296-303, 2013.

[7] O. N. Mercy and A. S. Peter, "Risky sexual behaviours among female in-school adolescents in delta, Nigeria: self-esteem, parental involvement and religiosity as predictors," European Scientific Journal, vol. 10, no. 31, pp. 157-177, 2014.

[8] N. Fentahun and A. Mamo, "Risky sexual behaviors and associated factors among male and female students in Jimma Zone preparatory schools, South West Ethiopia: comparative study," Ethiopian Journal of Health Sciences, vol. 24, no. 1, pp. 59-68, 2014.

[9] E. Kosunen, R. Kaltiala-Heino, M. Rimpelä, and P. Laippala, "Risk-taking sexual behaviour and self-reported depression in middle adolescence - A school-based survey," Child: Care, Health and Development, vol. 29, no. 5, pp. 337-344, 2003.
[10] G. Tura, F. Alemseged, and S. Dejene, "Risky sexual behavior and predisposing factors among students of Jimma university, Ethiopia," Ethiopian Journal of Health Sciences, vol. 22, no. 3, pp. 170-180, 2012.

[11] Aids HI V, “HIV/AIDS," STDs, \& STIs, vol. 4, no. 9, p. 6113, 2013.

[12] S. Campus, S. Town, A. Kebede, B. Molla, and H. Gerensea, "Assessment of risky sexual behavior and practice among Aksum University students," BMC Research Notes, pp. 7-12, 2018.

[13] A. F. Dadi and F. G. Teklu, "Risky sexual behavior and associated factors among grade 9-12 students in Humera secondary school, western zone of Tigray, NW Ethiopia, 2014," Science Journal of Public Health, vol. 2, no. 5, pp. 410-416, 2014.

[14] B. Soboka and G. Kejela, "Assessment of risky sexual behaviors among Arba Minch University Students, Arba Minch Town, Snnpr, Ethiopia," Journal of Child and Adolescent Behavior, vol. 3, no. 2, pp. 2-7, 2015.

[15] W. Mulu, M. Yimer, and B. Abera, "Sexual behaviours and associated factors among students at Bahir Dar University: A cross sectional study," Reproductive Health, vol. 11, no. 1, pp. 112, 2014.

[16] UNAIDS Report on the global AIDS epidemic - 2012. 2012.

[17] A. O. Adewuya, B. A. Ola, O. O. Aloba, B. M. Mapayi, and O. O. Oginni, "Depression amongst Nigerian university students: Prevalence and sociodemographic correlates," Social Psychiatry and Psychiatric Epidemiology, vol. 41, no. 8, pp. 674-678, 2006.

[18] M. W. Waller, D. D. Hallfors, C. T. Halpern, B. J. Iritani, C. A. Ford, and G. Guo, "Gender differences in associations between depressive symptoms and patterns of substance use and risky sexual behavior among a nationally representative sample of U.S. adolescents," Archives of Women's Mental Health, vol. 9, no. 3, pp. 139-150, 2006.

[19] A. Thapar, S. Collishaw, D. S. Pine, and A. K. Thapar, "Depression in adolescence," The Lancet, vol. 379, no. 9820, pp. 10561067, 2012.

[20] R. Gupta, M. Dandu, L. Packel et al., "Depression and HIV in Botswana: A population-based study on gender-specific socioeconomic and behavioral correlates," PLoS ONE, vol. 5, no. $12,2010$.

[21] M. R. Khan, J. S. Kaufman, B. W. Pence et al., "Depression, sexually transmitted infection, and sexual risk behavior among young adults in the United States," Archives of Pediatrics and Adolescent Medicine, vol. 163, no. 7, pp. 644-652, 2009.

[22] M. Nduna, R. K. Jewkes, K. L. Dunkle, N. P. J. Shai, and I. Colman, "Associations between depressive symptoms, sexual behaviour and relationship characteristics: a prospective cohort study of young women and men in the Eastern Cape, South Africa," Journal of the International AIDS Society, vol. 13, no. 1, article 44, 2010.

[23] C. J. Othieno, R. Okoth, K. Peltzer, S. Pengpid, and L. O. Malla, "Risky HIV sexual behaviour and depression among University of Nairobi students," Annals of General Psychiatry, vol. 14, no. 16, pp. 1-8, 2015.

[24] N. Regassa and S. Kedir, "Attitudes and practices on HIV preventions among students of higher education institutions in Ethiopia: the case of Addis Ababa University," East African Journal of Public Health, vol. 8, no. 2, pp. 828-840, 2011.

[25] A. Derese, A. Seme, and C. Misganaw, "Assessment of substance use and risky sexual behaviour among Haramaya University Students, Ethiopia," Science Journal of Public Health, vol. 2, no. 2, pp. 102-110, 2014. 
[26] F. Toosi, C. Rahimi, and S. Sajjadi, "Psychometric properties of beck depression inventory-II for high school children in Shiraz City, Iran," International Journal of School Health, vol. 4, no. 3, Article ID e41069, 2017.

[27] C. Sullivan, N. Martin, C. White, and D. Newbury-Birch, "Assessing the delivery of alcohol screening and brief intervention in sexual health clinics in the north east of England," $B M C$ Public Health, vol. 17, no. 1, pp. 1-8, 2017.

[28] J. J. N. Noubiap, J. R. N. Nansseu, S. T. Ndoula et al., "Prevalence and correlates of HIV-risky sexual behaviors among students attending the Medical and Social Welfare Center of the University of Maroua, Cameroon Public Health," BMC Research Notes, vol. 8, no. 1, pp. 1-11, 2015.

[29] A. H. Mavhandu-Mudzusi and T. T. Asgedom, "The prevalence of risky sexual behaviours amongst undergraduate students in Jigjiga University, Ethiopia," Health SA Gesondheid, vol. 21, pp. 179-186, 2016.

[30] A. Fantahun, S. Wahdey, and K. Gebrekirstos, "Risky sexual behaviors and predisposing factors among Mekelle University College of business and economics students, Mekelle, Tigray, Ethiopia, 2013: cross sectional study," American Journal of Advanced Drug Delivery, 2013.

[31] O. H. Rahamefy, M. Rivard, M. Ravaoarinoro, L. Ranaivoharisoa, A. J. Rasamindrakotroka, and R. Morisset, "Sexual behaviour and condom use among university students in Madagascar," Sahara J, vol. 5, no. 1, pp. 28-35, 2008.

[32] A. Campo-Arias, G. A. Ceballo, and E. Herazo, "Prevalence of pattern of risky behaviors for reproductive and sexual health among middle- and high-school students," Revista LatinoAmericana de Enfermagem, vol. 18, no. 2, pp. 170-174, 2010.

[33] G. Andargie, A. Kassu, F. Moges et al., "Low prevalence of HIV infection, and knowledge, attitude and practice on HIV/AIDS among high school students in Gondar, Northwest Ethiopia," Ethiopian Journal of Health Development, vol. 21, no. 2, pp. 2-5, 2007.

[34] A. Henok, A. Kassa, A. Lenda, A. Nibret, and T. Lamaro, "Behavior knowledge, attitude and practice of risky sexual behavior and condom utilization among regular students of MizanTepi University, South West," Journal of Child and Adolescent Behavior, vol. 3, no. 5, pp. 3-6, 2015.

[35] J. A. Lehrer, L. A. Shrier, S. Gortmaker, and S. Buka, "Depressive symptoms as a longitudinal predictor of sexual risk behaviors among US middle and high school students," Pediatrics, vol. 118, no. 1, pp. 189-200, 2006.

[36] P. Seth, S. N. Patel, J. M. Sales, R. J. DiClemente, G. M. Wingood, and E. S. Rose, "The impact of depressive symptomatology on risky sexual behavior and sexual communication among African American female adolescents," Psychology, Health \& Medicine, vol. 16, no. 3, pp. 346-356, 2011.

[37] L. A. Shrier, S. K. Harris, and W. R. Beardslee, "Temporal associations between depressive symptoms and self-reported sexually transmitted disease among adolescents," Archives of Pediatrics \& Adolescent Medicine, vol. 156, no. 6, pp. 599-606, 2002.

[38] N. M. Tumwesigye, L. Atuyambe, and R. K. Wanyenze, "Alcohol consumption and risky sexual behaviour in the fishing communities: Evidence from two fish landing sites on Lake Victoria in Uganda," BMC Public Health, vol. 12, no. 1, article 1069, p. 1, 2012.

[39] M. P. Davoren, F. Shiely, M. Byrne, and I. J. Perry, "Hazardous alcohol consumption among university students in Ireland: A cross-sectional study," BMJ Open, vol. 5, no. 1, Article ID 006045, 2015.
[40] L. A. J. Scott-Sheldon, M. P. Carey, and K. B. Carey, "Alcohol and risky sexual behavior among heavy drinking college students," AIDS and Behavior, vol. 14, no. 4, pp. 845-853, 2010. 


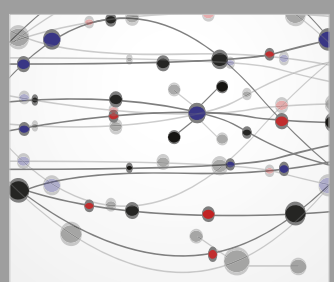

The Scientific World Journal
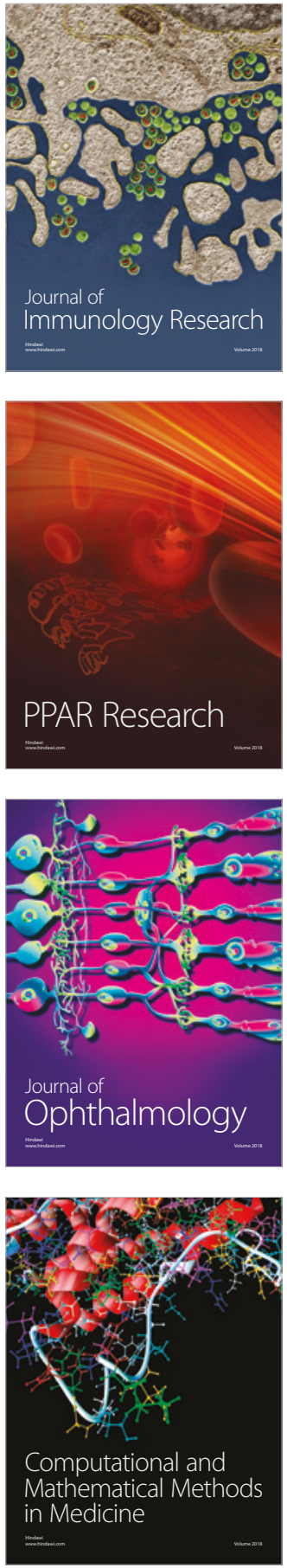

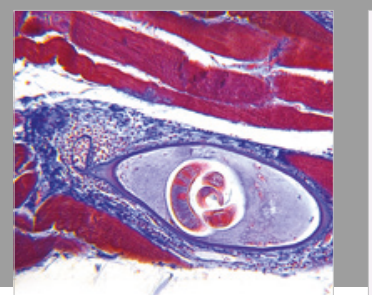

Gastroenterology Research and Practice

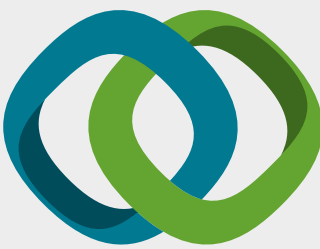

\section{Hindawi}

Submit your manuscripts at

www.hindawi.com
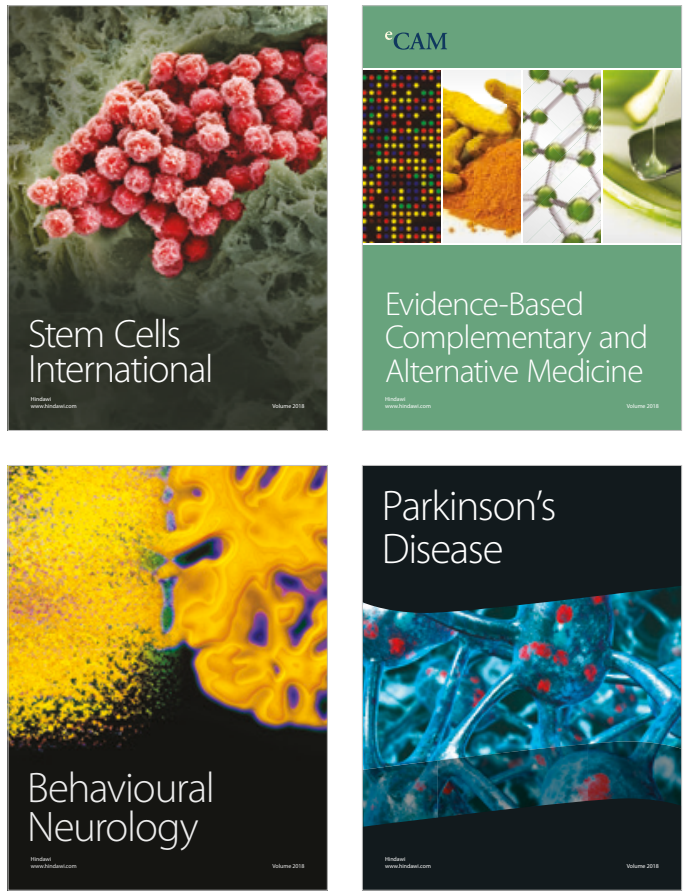

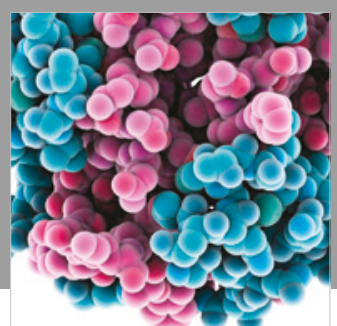

ournal of

Diabetes Research

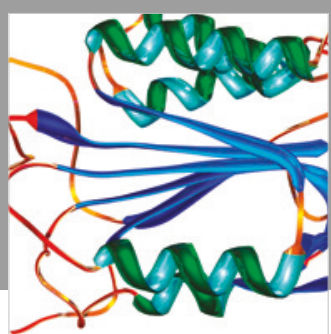

Disease Markers
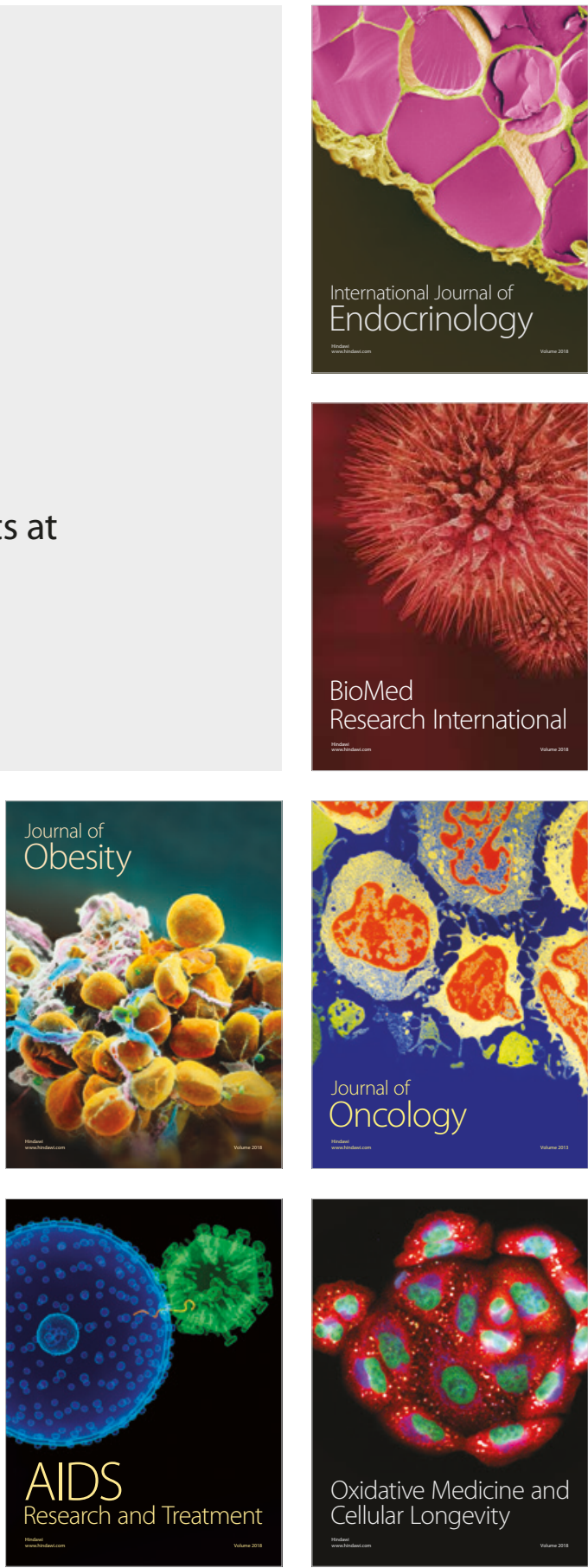